TERAPI MODALITAS KEPERAWATAN PIJAT PUNGGUNG SEBAGAI PERAWATAN DAYA INGAT (BAHASA) LANSIA DI UNIT PELAKSANA TEKNIS PANTI SOSIAL LANJUT USIA KABUPATEN JEMBER

\title{
(BACK MASSAGE MODALITY THERAPY FOR ELDERLY MEMORY CARE (LANGUAGE) IN JEMBER LONG-TERM CARE FACILITY)
}

\author{
Kushariyadi \\ Program Studi Ilmu Keperawatan Universitas Jember \\ Jl. Kalimantan No. 37 Jember 68121 \\ e-mail:kushariyadi@unej.ac.id
}

\begin{abstract}
ABSTRAK
Kata kunci:

daya ingat (bahasa)

lansia

terapi modalitas ke-

perawatan pijat

punggung

Proses penuaan dapat menurunkan daya ingat pada lansia. Lansia bertambah usia diharapkan daya ingat terpelihara dengan baik sehingga fungsi dan kualitas hidup lansia sebagai individu kompleks dan unik dapat berfungsi dan sejahtera. Permasalahan di UPT PSLU Kabupaten Jember terdapat penurunan daya ingat pada lansia. Lansia menyatakan permasalahan mengenai penurunan daya ingat yang dialami dan dirasakan sudah sejak lama. Sampai saat ini perawatan terhadap penurunan daya ingat pada lansia di UPT PSLU Jember menggunakan terapi modalitas keperawatan pijat punggung masih belum pernah diberikan. Jenis penelitian eksperimen semu dengan rancangan one group prepost test treatment design bertujuan membandingkan kelompok perlakuan sebelum diberi intervensi terapi modalitas keperawatan pijat punggung dengan setelah diberi intervensi. Tujuan penelitian mengetahui pengaruh terapi modalitas keperawatan pijat punggung sebagai perawatan daya ingat (bahasa) lansia. Tehnik pengambilan sampel menggunakan simple random sampling pada lansia di UPT PSLU Jember sebanyak 12 responden pada 2016. Hasil analisis Wilcoxon sign rank test didapatkan nilai daya ingat (bahasa) p $=0,034$ maka disimpulkan ada perbedaan daya ingat (bahasa) lansia yang bermakna antara sebelum dan setelah pemberian terapi modalitas keperawatan pijat punggung. Perawat dan care giver keluarga secara bersama-sama memberikan terapi alternatif menggunakan terapi modalitas keperawatan pijat punggung untuk perawatan pasien secara individual dan holistik agar lansia menjadi tetap produktif.
\end{abstract}

\begin{tabular}{l}
\hline \\
\hline Keywords: \\
back massage mo- \\
dality therapy \\
elderly \\
memory (langu- \\
age)
\end{tabular}

age)

\section{ABSTRACT}

The aging process can reduce the memory in the elderly. Elderly expected memory gets older well maintained so that the function and quality of life of the elderly as a complex and unique individuals to function and prosper. Problem in UPT PSLU Jember is memory loss in the elderly. Elderly expressed concerns about memory loss experienced and perceived long ago. Until now, treatment of memory loss in the elderly in UPT PSLU Jember using nursing a back massage modality therapy has not been given. Type of quasi-experimental research design with one group pre-post test design treatment aimed to compare before treatment group were given nursing intervention modality therapy back massage with after being given intervention. This study aimed to influence nursing a back massage modality therapy in the treatment of memory (language) of the elderly. Sampling techniques used simple 
random sampling of the elderly in UPT PSLU Jember much as 12 respondents in 2016. The results of the analysis Wilcoxon signed rank test obtained value memory (language) $p=0.034$, we conclude there is difference memory (language) of elderly significantly between before and after nursing a back massage modality therapy. Nurses and care giver family jointly provide alternative therapies using the back massage modality therapy for patient care individually and holistically so that elderly to remain productive.

\section{PENDAHULUAN}

Lansia secara fisiologis terjadi penurunan fungsi kognitif (daya ingat) yang bersifat ireversibel. Kondisi ini disebabkan oleh proses penuaan dan perubahan degeneratif yang mungkin progresif (Gething et al, 2004; Lovell, 2006). Masalah mengenai perubahan terkait usia pada proses penuaan dapat menurunkan fungsi kognitif(daya ingat) pada lansia karena lansia yang semakin bertambah usia diharapkan fungsi daya ingat dapat terpelihara dengan baik sehingga fungsi dan kualitas hidup lansia sebagai individu kompleks dan unik dapat berfungsi dan sejahtera. Permasalahan di Unit Pelaksana Teknis Panti Sosial Lanjut Usia (UPT PSLU) Kabupaten Jember bahwa terdapat penurunan fungsi kognitif (daya ingat) pada lansia. Lansia menyatakan bahwa permasalahan mengenai penurunan daya ingat yang dialami dan dirasakan sudah sejak lama. Sampai saat ini perawatan terhadap penurunan daya ingat pada lansia di UPT PSLU Jember menggunakan terapi modalitas keperawatan pijat punggung masih belum pernah diberikan.

Insiden lansia di Brazil yang mengalami penurunan fungsi kognitif berjumlah 123 sampel lansia (Montoril et al, 2015). Insiden lansia di Amerika yang mengalami penurunan fungsi kognitif (daya ingat) berjumlah 47 lansia berusia 50-67 tahun (Lesch, 2003). Insiden lansia di Italia yang mengalami penurunan daya ingat terdapat 20 sampel lansia berusia 60-70 tahun (Cavallini et al, 2003). Insiden lansia di Netherlands yang mengalami penurunan daya ingat berjumlah 93 lansia dengan usia 65 tahun (Ekkers et al, 2011). Insiden lansia di Norwaygia yang mengalami penurunan daya ingat terdapat $27 \%$ dengan diagnosis gangguan daya ingat subyektif dan sebanyak 19 lansia berusia rerata 60,9 tahun (Braekhus et al, 2011). Insiden lansia di Hongkong yang mengalami penurunan daya ingat daya berjumlah 20 lansia berusia 80 tahun (Lim, et al, 2012). Penelitian pada anak sekolah dasar di Surabaya terdapat peningkatan daya ingat yang signifikan (Erviyanti, 2007). Insiden lansia di Panti Werdha Mojopahit Mojokerto yang mengalami penurunan daya ingat dengan usia antara 58-91 tahun sejumlah 30 sampel
(Kushariyadi, 2013).

Penyebab penurunan fungsi kognitif (daya ingat) lansia secara fisiologis antara lain karena terjadi proses penuaan dan perubahan degeneratif yang progresif dan bersifat ireversibel (Gething et al, 2004; Lovell, 2006). Hal ini dipengaruhi oleh lingkungan, pengalaman hidup dan faktor sosio emosional seperti perilaku, harapan, dan motivasi. Motivasi dapat memengaruhi proses kognitif (daya ingat) (Carstensen et al, 2006; Ormrod, 2009). Kemampuan kognitif juga dipengaruhi oleh kesehatan, emosi, kognitif, kepribadian, dan karakteristik psikologi (Hofer et al, 2006; Kramer et al, 2006). Penurunan daya ingat lansia dari segi bahasa antara lain lansia kesulitan mengulangi kata yang diucapkan oleh perawat dan kesulitan mengikuti perintah yang diberikan. Akibat dari penurunan fungsi kognitif(daya ingat) lansia jika tidak dilakukan tindakan akan terjadi penurunan daya ingat pada lansia (Abraham et al, 1997; Miller, 2009). Hal ini sesuai dengan teori kemunduran yang menyatakan dengan bertambahnya usia, daya ingat akan mengalami penurunan. Perubahan neuron dan sinaps otak sebagai pembentukan daya ingat juga mengalami penurunan seiring bertambahnya usia (Solso et al, 2008; Wade et al, 2008). Akibat lainnya yaitu informasi yang tidak cepat dipindahkan ke daya ingat jangka pendek akan menghilang (Hartley, 2006; Solso et al, 2008; Wade et al, 2008). Dampak lain terjadi penurunan kemampuan beradaptasi terhadap perubahan dan stres lingkungan sehingga menyebabkan gangguan psikososial, mencetuskan atau memperburuk kemunduran fisik, terjadi penurunan kualitas hidup dan menghambat pemenuhan tugas-tugas perkembangan lansia (Stanley \& Beare, 2007).

Salah satu upaya yang dapat dilakukan untuk mengatasi permasalahan pada lansia yaitu memberikan terapi modalitas keperawatan pijat punggung untuk merawat daya ingat lansia di unit pelayanan teknis panti sosial lanjut usia Kabupaten Jember. Terapi modalitas keperawatan pijat punggung merupakan tindakan manipulasi yang sistematis pada jaringan lunak tubuh dengan sentuhan dan tekanan berirama untuk memberikan efek kesehatan (Sritoomma et al, 2013). 


\section{METODE}

Jenis penelitian termasuk dalam eksperimen semu (quasy exsperiment). Rancangan penelitian menggunakan one group pre-post test treatment design bertujuan untuk membandingkan kelompok perlakuan sebelum diberi intervensi dengan setelah diberi intervensi pijat punggung.

Tehnik pengambilan sampel penelitian menggunakan simple random sampling. Randomisasi menggunakan simple random sampling untuk memilih sampel kelompok perlakuan. Sampel penelitian meliputi lansia yang bertempat tinggal di UPT PSLU Jember. Besar sampel penelitian sebanyak 12 responden kelompok perlakuan. Karakteristik responden meliputi: 1) usia 60-90 tahun; 2) lansia yang dapat dilakukan pengukuran daya ingat (bahasa); 3) kooperatif; 4) bersedia menjadi responden.

Penelitian dilakukan pada April 2016. Instrumen penelitian menggunakan kuesioner peningkatan fungsi kognitif (daya ingat) yaitu MMSE. Instrumen ini berisi item pertanyaan atau perintah mengenai perhatian dan kalkulasi. Mengisi instrumen peningkatan fungsi kognitif dilakukan sekitar 5-10 menit. Sedangkan terapi modalitas keperawatan pijat punggung dilakukan sekitar 10 menit setiap hari selama 7 hari.

Prosedur pengambilan data meliputi: 1) mengadakan perijinan ke UPT PSLU Jember; 2) memberikan penjelasan kepada sejumlah lansia yang memenuhi kriteria tentang maksud dan tujuan kegiatan; 3) menyiapkan lembar persetujuan (informed consent) yang disetujui oleh lansia untuk menjadi responden; 4) uji coba instrumen menggunakan instrumen peningkatan fungsi kognitif (daya ingat) yang telah dimodifikasi; 5) penentuan besar sampel dan menentukan responden menjadi 1 kelompok (perlakuan); 6) melakukan pre-test pada hari ke-1 menggunakan instrumen peningkatan daya ingat (bahasa) terhadap kelompok untuk diukur daya ingat (bahasa); 7) kelompok diberikan intervensi terapi modalitas keperawatan pijat punggung setiap hari selama 7 hari dengan waktu sekitar 10 menit; 8) melakukan post-test pada hari terakhir menggunakan instrumen peningkatan daya ingat (bahasa) terhadap kelompok untuk diukur daya ingat (bahasa); 9) hasil nilai pre-test dan post-test dicatat dan disimpan peneliti untuk diolah dan dianalisis.

Uji analisis statistik untuk membandingkan hasil antara pre-test dan post-test menggunakan Wilcoxon sign rank test dengan tingkat kemaknaan $\mathrm{p}<0,05$.

\section{HASIL}

\section{Karakteristik Responden}

Tabel 1 menunjukkan bahwa sebagian besar responden berjenis kelamin perempuan sebanyak 7 orang $(58,3 \%)$. Riwayat pendidikan responden sebagian besar berpendidikan SMA sebanyak 6 orang $(50 \%)$. Riwayat pekerjaan responden sebagian besar sebagai petani sebanyak 6 orang (50\%). Status pernikahan reponden sebagian besar berstatus janda/duda sebanyak 11 orang $(91,7 \%)$. Lama tinggal di panti responden sebagian besar selama 0-5 tahun sebanyak 9 orang (75\%). Usia responden sebagian besar berkategori elderly (60-74 tahun) sebanyak 9 orang $(25 \%)$.

\section{Uji Normalitas}

Tabel 2 menunjukkan bahwa hasil perhitungan menggunakan uji Kolmogorov-Smirnov pada daya ingat lansia sebelum perlakuan pada bahasa $\mathrm{p}=0,001$. Karena nilai $\mathrm{p}<0,05$ maka disimpulkan data skor daya ingat (bahasa) lansia sebelum perlakuan mempunyai sebaran tidak normal.

\section{Nilai Daya Ingat (Bahasa)}

Tabel 3 menunjukkan bahwa rerata sebelum perlakuan yaitu 8,58 dan setelah perlakuan yaitu 9,08 menunjukkan daya ingat (bahasa) yang dihasilkan adalah meningkat.

Hasil analisis menggunakan Wilcoxon sign rank test didapatkan nilai signifikan $\mathrm{p}=0,034$ karena nilai $\mathrm{p}<0,05$ maka disimpulkan ada perbedaan daya ingat (bahasa) lansia yang bermakna antara sebelum dan setelah pemberian terapi modalitas keperawatan pijat punggung.

\section{PEMBAHASAN}

\section{Nilai Daya Ingat (Bahasa)}

Tabel 3 menunjukkan terdapat perbedaan signifikan $(p=0,034)$ daya ingat (bahasa) lansia yang bermakna antara sebelum dan setelah pemberian terapi modalitas keperawatan pijat punggung. Perbedaan tampak pada hasil nilai rerata daya ingat (bahasa) lansia sebelum diberikan perlakuan sebesar 8,58 . Namun setelah diberikan perlakuan nilai rerata daya ingat (bahasa) lansia meningkat menjadi 9,08. Terdapat peningkatan selisih nilai rerata antara pretest dan post-test sebesar 0,5.

Secara keseluruhan berarti pemberian terapi modalitas keperawatan pijat punggung berpengaruh terhadap daya ingat (bahasa) lansia. Hal ini disebabkan karena lansia menggunakan bahasa dalam keseharian 
Tabel 1. Karakteristik Responden Berdasarkan Jenis Kelamin, Riwayat Pendidikan, Riwayat Pekerjaan, Status Pernikahan, Lama Tinggal Di Panti, Dan Usia

\begin{tabular}{|c|c|c|c|}
\hline \multirow[t]{2}{*}{ No } & \multirow{2}{*}{$\begin{array}{l}\text { Karakteristik } \\
\text { Responden }\end{array}$} & \multicolumn{2}{|c|}{ Perlakuan } \\
\hline & & Frekuensi & Persentase \\
\hline \multirow[t]{3}{*}{1} & Jenis kelamin: & & \\
\hline & Laki-laki & 5 & 41,7 \\
\hline & Perempuan & 7 & 58,3 \\
\hline \multirow[t]{5}{*}{2} & Riwayat pendidikan: & & \\
\hline & SD & 2 & 16,7 \\
\hline & SMP & 4 & 33,3 \\
\hline & SMA & 6 & 50,0 \\
\hline & PT (Perguruan Tinggi) & 0 & 0 \\
\hline \multirow[t]{5}{*}{3} & Riwayat pekerjaan: & & \\
\hline & Tidak bekerja & 1 & 8,3 \\
\hline & Petani & 6 & 50,0 \\
\hline & Wiraswasta & 3 & 25,0 \\
\hline & Lain-lain & 2 & 16,7 \\
\hline \multirow[t]{3}{*}{4} & Status pernikahan: & & \\
\hline & Menikah & 1 & 8,3 \\
\hline & Janda/duda & 11 & 91,7 \\
\hline \multirow[t]{4}{*}{5} & Lama tinggal di panti: & & \\
\hline & 0-5 tahun & 9 & 75,0 \\
\hline & $6-10$ tahun & 2 & 16,7 \\
\hline & $>10$ tahun & 1 & 8,3 \\
\hline \multirow[t]{3}{*}{6} & Usia: & & \\
\hline & Elderly (60-74 tahun) & 9 & 74,8 \\
\hline & Old (75-90 tahun) & 3 & 25,0 \\
\hline
\end{tabular}

Tabel 2. Hasil Uji Normalitas Daya Ingat (Bahasa) Sebelum Perlakuan

\begin{tabular}{lcccccc}
\hline Daya Ingat & & \multicolumn{5}{c}{ Pre-test } \\
\hline & Mean & Median & $\begin{array}{c}\text { Std. } \\
\text { Deviation }\end{array}$ & Minimum & Maximum & $\begin{array}{c}\text { Kolmogorov- } \\
\text { Smirnov }\end{array}$ \\
\hline Bahasa & 8,58 & 9,00 & 0,90 & 6,00 & 9,00 & 0,000 \\
\hline
\end{tabular}

Tabel 3. Nilai Pre-Test Dan Post-Test Daya Ingat (Bahasa)

\begin{tabular}{lcccc}
\hline \multicolumn{1}{c}{ Daya Ingat (Bahasa) } & $\mathbf{n}$ & $\begin{array}{c}\text { Median } \\
\text { (Min-Max) }\end{array}$ & Rerata \pm SD & p \\
\hline $\begin{array}{l}\text { Sebelum diberi terapi } \\
\text { modalitas keperawatan pijat } \\
\text { punggung }\end{array}$ & 12 & $(6,00-9,00)$ & $8,58 \pm 0,90$ & 0,034 \\
\hline $\begin{array}{l}\text { Setelah diberi terapi modalitas } \\
\text { keperawatan pijat punggung }\end{array}$ & 12 & $(7,00-10,00)$ & $9,08 \pm 0,90$ \\
\hline
\end{tabular}


aktivitas kegiatan hidupnya, misalnya berkomunikasi, berpikir dan berperilaku.

Penelitian Cavallini et al (2003) menunjukkan memori kerja meningkat saat lansia menyelesaikan tugas dari segi bahasa menggunakan kumpulan daftar kata, penamaan dan mengikuti perintah. Hal ini dipengaruhi kemampuan lansia dalam mengevaluasi kembali tugas dari segi bahasa menggunakan strategi belajar terkait cara berpikir dan melakukan tindakan pada situasi berbeda misalnya dalam aktivitas kegiatan hidup harian.

Penelitian Bottirolli et al (2008) menunjukkan pelatihan memori diberikan ke dalam aktivitas kegiatan hidup harian. Strategi pelatihan yang dipelajari dalam aktivitas kegiatan hidup harian meningkatkan memori kerja lansia dan memelihara efek latihan jangka panjang. Lansia menjalani pelatihan memori menunjukkan pengetahuan memori lebih besar dan sedikit keluhan.

Penelitian Engvig et al (2010) menunjukkan efek jangka panjang pelatihan memori terkait cara meningkatkan memori kerja ke dalam fungsi aktivitas kegiatan hidup harian yang berfungsi sebagai mekanisme dalam melindungi kerusakan fungsi kognitif(memori). Penelitian menunjukkan pelatihan memori meningkatkan memori kerja.

Sesuai dengan teori hubungan terapeutik memandang bahasa dapat memengaruhi pemikiran, berpikir dapat memengaruhi tindakan, berpikir dan bertindak dapat memengaruhi perasaan. Sehingga bahasa adalah model utama dalam memengaruhi pikiran dan perasaan (Basford et al, 2006; Potter et al, 2009).

Pendapat peneliti bahwa meskipun lansia di UPT PSLU Kabupaten Jember memiliki riwayat pendidikan formal sebagian besar adalah sekolah dasar, akan tetapi hal tersebut tidak menyurutkan lansia dalam melatih kemampuan strategi keterampilan belajar yaitu dengan meningkatkan kemampuan strategi keterampilan pelatihan dan pembelajaran melalui pendidikan informal dengan cara melaksanakan aktifitas kegiatan hidup harian terkait bahasa.

Hasil nilai bahasa menunjukkan perubahan berarti terhadap peningkatan memori (Maas et al, 2011). Penelitian Matthews et al (1999) memperlihatkan kelompok lansia banyak yang mempertahankan fungsi intelektualnya. Pendidikan formal melindungi lansia dari penurunan fungsi kognitif (memori) terkait penuaan, walaupun pendidikan yang dijalani lansia berlangsung selama beberapa tahun sebelumnya. Penelitian Zhu et al (1998) menunjukkan pendidikan formal membantu pada fungsi kognitif (memori) lansia. Selain itu lansia mampu memperbaiki penampilan intelektualnya melalui pendidikan informal dengan latihan dan pengalaman melakukan berbagai tugas dalam aktivitas kegiatan hidup harian. Penelitian Calero et al (2007) menunjukkan tingkat pendidikan (jumlah tahun di sekolah) dan kemampuan bahasa dapat memprediksi peningkatan daya ingat setelah pelatihan memori. Penelitian Lim et al (2012) dalam kriteria inklusi menggunakan responden lansia dengan tingkat pendidikan berkisar dari tidak sekolah sampai 4 tahun sekolah dasar.

Sebagaimana peran perawat pada hubungan terapeutik perawat-pasien adalah perawat sebagai pendidik (teacher) bahwa perawat berupaya memberikan penyuluhan, pendidikan, pelatihan, dan bimbingan pada pasien atau keluarga dalam mengatasi masalah kesehatan, dibimbing ke arah pertumbuhan dan perkembangan kepribadian. Perawat dapat membantu pasien belajar secara formal maupun informal. Perawat membangkitkan minat pasien terhadap sesuatu hal yang harus diketahui oleh pasien dan cara untuk menghadapi informasi tersebut (Alligood et al, 2006; Basford et al, 2006; Videbeck, 2011).

Hal ini sesuai kompetensi fungsi kognitif (memori) lansia yaitu kemampuan melakukan aktivitas kegiatan harian terus-menerus, merupakan hasil penerapan proses kognitifberulang di berbagai situasi. Kecerdasan terkristalisasi digunakan jika strategi penyelesaian tugas yang dilakukan memerlukan pengetahuan yang pernah dipelajari selama kehidupan lansia. Kecerdasan cairan digunakan saat strategi penyelesaian tugas yang dilakukan tidak berhubungan dengan pengalaman atau pengetahuan sebelumnya (Maas et al, 2011).

Bahasa dalam komunikasi terapeutik digunakan mengidentifikasi obyek dan konsep yang didiskusikan. Urutan dan makna terbentuk dengan menyusun perkataan menjadi frase dan kalimat yang dapat dipahami oleh pembicara dan pendengar. Penggunaan bahasa di dalam hubungan terapeutik, perawat mendorong pasien bercerita mengenai kegiatan aktivitasnya. Melalui cara ini, perawat memahami konteks kehidupan pasien dan dapat membantu permasalahannya (Potter et al, 2009; Videbeck, 2011)

\section{SIMPULAN}

Pemberian intervensi keperawatan terapi modalitas keperawatan pijat punggung dapat meningkatkan daya ingat lansia di UPT PSLU Kabupaten Jember. 
SARAN

Dari perspektif keperawatan, praktik keperawatan memberikan tantangan dan kesempatan bagi perawat dan care giver keluarga secara bersama-sama memberikan terapi alternatif dengan menggunakan teknologi untuk memberikan perawatan pasien secara lebih individual dan holistik.

Lansia di UPT PSLU Kabupaten jember secara teratur, efektif, kreatif, dan terus-menerus melatih kemampuan registrasi atau mengulang informasi yang didapat, agar lansia menjadi tetap produktif. Hal ini sesuai tujuan komunikasi terapeutik antara lain memotivasi dan mengembangkan pribadi pasien ke arah konstruktif dan adaptif.

\section{KEPUSTAKAAN}

Abraham, C., \& Shanley, E. 1997. Psikologi sosial untuk perawat. Jakarta: EGC.

Alligood, M.R., \& Tomey, A.M. 2006. Nursing theorists and their work. 7th Ed. St. Louis Missouri: Mosby.

Bahrudin, M. 2011. Pemeriksaan klinis di bidang penyakit syaraf. Malang: UMM Pres.

Basford, L., \& Slevin, D. 2006. Teori dan Praktik Keperawatan: Pendekatan Integral pada Asuhan Pasien. Jakarta: EGC.

Bottiroli, S., Cavallini, E., \& Vecchi, T. 2008. Longterm effects of memory training in the elderly: A longitudinal study. Archives of Gerontology and Geriatrics 47 (2008) 277-289. http:www.sciencedirect.com. Diakses 8 Juli 2016.

Braekhus, A., Ulstein, I., Wyller, T.B., Engedal, K., 2011. The Memory Clinic-outpatient assessment when dementia is suspected. Tidsskr. Nor. laegeforen. 131, 2254-2257. www.ncbi.nlm.nih.gov/ pubmed/22085955. Diakses 7 Juli 2016.

Cartensen, L.L., Mikels, J.A., \& Mather, M. 2006. Aging and the Intersection of Cognition, Motivation, and Emotion. In J.E. Birren $\&$ K.W. Schaie (Eds.), Handbook of the Psychology of Aging (6th ed., pp. 343362). San Diego: Academic Press. psychology.stanford.edu/ lifespan/ publications.htm. Diakses 2 Juli 2016.

Calero, M.D., \& Navarro, E. 2007. Cognitive plasticity as a modulating variable on the effects of memory training in elderly persons. Archives of Clinical Neuropsychology 22 (2007) 63-72. http:www.sciencedirect.com. Diakses 8 Agustus 2016.

Cavallini, E., Pagnin, A., Vecchi, T. 2003. Aging and Everyday Memory: the Beneficial Effect of Memory Training. Arch. Gerontol. Geriatr. 37 (2003) 241-257. $<$ www.else vier.com/locate/archger $>$. http:www.sciencedirect.com. Diakses 4 Juli 2016.

Ekkers, W., Korrelboom, K., Huijbrechts, I., Smits, N., Cuijpers, P., Gaag, M.V.D. 2011. Competitive Memory Training for treating depression and rumination in depressed older adults: A randomized controlled trial. Behavior Research and Therapy 49 (2011) 588-596. Elsevier. http:www.sciencedirect.com. Diakses 4 Juli 2016.

Engvig, A., Fjell, A.M., Westlye, L.T., Moberget, T., Sundseth, O., Larsen, V.A., \& Walhovd, K.B. 2010. Effects of memory training on cortical thickness in the elderly. NeuroImage 52 (2010) 1667- 1676. http:www.sciencedirect.com. Diakses 4 Juli 2016.

Erviyanti, A.D. 2007. Peningkatan daya ingat dengan metode belajar hafalan system asosiasi: Penelitian true eksperimen dalam bidang kesehatan mental sekolah di SDN Keputran 3 Surabaya. Tesis. Universitas Airlangga. Surabaya. <http:// ADLN.com/>. library@lib.unair.ac.id. Diakses 2 Juli 2016.

Gething, L., Fethney, J., McKee, K., Persson, L.O., Goff, M., Church-ward, M. 2004. Validation of the reactions to ageing questionnaire: assessing similarities across several countries. Journal of gerontological nursing. 30(9), 47-54. www. conceptwiki.org/.../ Concept:f2db3afe-7ebb-11df-9387001517. Diakses 4 Juli 2016.

Ginsberg, L. 2008. Lecture notes: Neurology. Jakarta: Penerbit Erlangga.

Hartley, A. 2006. Changing Role of the Speed of Processing Construct in the Cognitive Psychology of Human Aging. In J.E. Birren $\&$ K.W. Schaie (Eds.), Handbook of the Psychology of Aging (6th ed., pp. 183207). San Diego: Academic Press. https://tspace.library.utoronto.ca/.../ Burton_Christine_M_201111_Ph. Diakses 7 Juli 2016. 
Hofer, S.M., \& Sliwinski, M.J. 2006. Design and Analysis of Longitudinal Studies on Aging. In J.E. Birren \& K.W. Schaie (Eds.), Handbook of the Psychology of Aging (6th ed., pp. 17-37). San Diego: Academic Press. psycnet.apa.org/journals/pag/26/4/778/. Diakses 2 Juli 2016.

Holland, B., \& Pokorny, M.E. 2001. Slow-stroke back massage: its effect on patients in a rehabilitation setting. Rehabil Nurs. 2001 Sep-Oct, 26(5): 182-6. PubMed. http:// www.ncbi.nlm.nih.gov/pubmed/ 12035687. Diakses 8 Agustus 2016.

Kramer, A.F., Fabiani, M., \& Colcombe, S.J. 2006. Contributions of Cognitive Neuroscience to the Understanding of Behavior and Aging. In J.E. Birren \& K.W. Schaie (Eds.), Handbook of the Psychology of Aging (6th ed., pp. 17-37). San Diego: Academic Press. Diakses 7 Juli 2016

Kushariyadi. 2013. Intervensi (stimulasi memory) meningkatkan fungsi kognitif lansia. Jurnal Ners (Ners J.) Vol. 8, No.2, Oktober. Program Studi Ilmu Keperawatan FKp Unair bekerja sama dengan PPNI Propinsi Jawa Timur.

Lim, M.H.X., Liu, K.P.Y., Cheung, G.S.F., Kuo, M.C.C., Li, K.R., \& Tong, C.Y. 2012. Effectiveness of a Multifaceted Cognitive Training Programme for People with Mild Cognitive Impairment: A OneGroup Pre- and Posttest Design. Hong Kong Journal of Occupational Therapy (2012) 22, 3-8. http:www.sciencedirect.com. Diakses 2 Juli 2016.

Lesch, M.F. 2003. Comprehension and memory for warning symbols: Age-related differences and impact of training. Journal of Safety Research 34 (2003) 495 - 505. http:www.sciencedirect.com. Diakses 7 Juli 2016.

Lovell, M. 2006. Caring for the elderly: changing perceptions and attitudes. Journal of vascular nursing. 24(1), 22-26. www.sciencedirect.com/science/article/ pii/ S1062030305001688. Diakses 4 Juli 2016.

Lumbantobing, S.M. 2012. Neurologi klinik pemeriksaan fisik dan mental. Jakarta: Balai Penerbit FKUI.

Maas, M.L., Komalasari, R., Lusyana, A., Yuningsih, Y. 2011. Asuhan keperawatan geriatric: diagnosis NANDA, kriteria hasil NOC \& intervensi NIC. Jakarta: EGC.

Matthews., Cauley., Yaffe., \& Zmuda. 1999. Estrogen replacement therapy and cognitive decline in older community women. Journal of the American geriatrics society, 47(5), 518-523.

Miller, C.A. 2009. Nursing for wellness in older adults. 5th Edition ed. Philadelphia: Lippincott Williams \& Wilkins.

Mok, E., \& Woo, C.P. 2004. The effects of slowstroke back massage on anxiety and shoulder pain in elderly stroke patients. Complement Ther Nurs Midwifery. 2004 Nov, 10(4): 209-16. PubMed. http:/ /www.ncbi.nlm.nih.gov/pubmed/ 15519938. Diakses 8 Agustus 2016.

Montoril, MH., Lopes, MVO., Santana, RF., Sousa, VEC., Carvalho, PMO., Diniz, CM., Alves, NP., Ferreira, GL., Froes, NBM., $\&$ Menezes, AP. 2015. Clinical validation of the NANDA-I diagnosis of impaired memory in elderly patients. Applied nursing Research. http:// www.sciencedirect.com.sci-hub.cc/science/article/pii/S0897189715001688.

Ormrod, J.E. 2009. Psikologi pendidikan. Membantu siswa tumbuh dan berkembang. Ed. 6 . Jilid 1. Jakarta: Penerbit Erlangga.

Parker, M.E. \& Smith, M.C. 2010. Nursing Theories $\&$ Nursing Practice. 3rd. Ed. Philadelphia: Davis Company.

Potter, P.A., \& Perry, A.G. 2009. Fundamental keperawatan. Ed.7. Buku 1. Jakarta: Salemba Medika.

Smeltzer, S.C. 2001. Buku ajar keperawatan medical bedah Brunner \& Suddarth. Ed.8. Jakarta: EGC.

Solso, R.L., Maclin, O.H., \& Maclin, M.K. 2008. Psikologi kognitif. Ed. 8. Jakarta: Penerbit Erlangga.

Sritomma, N., Moyle, W., Cooke, M., \& O'Dwyer, S. (2013). The Effectiveness of Swedish Massage With Aromatic Ginger Oil In Treating Chronic Low Back Pain In Older Adults: A Randomized Controlled Trial. Journal Complementary Therapies In Medicine. Vol.22: 26-33.

Stanley, M., \& Beare, P.G. 2007. Buku Ajar Keperawatan Gerontik. Edisi 2. Jakarta: EGC

Videbeck, S.L. 2011. Psychiatric-mental health nursing. 5th ed. Philadelphia: Lippincott Wil- 
liams \& Wilkins.

Wade, C., \& Travis, C. 2008. Psikologi. Jilid 2. Ed. 9. Jakarta: Penerbit Erlangga.

Walgito, B. 2004. Pengantar psikologi umum. Ed.4. Yogyakarta: Penerbit Andi.

Zhu., Viitanen., Guo., Winblad., \& Fratiglioni. 1998. Blood pressure reduction, cardiovascular disease and cognitive decline in the mini-mental state examination in community population of normal very old people: a three year follow-up. Journal of clinical epidemiology. 51(5), 385-391. 